\title{
Numerical Tests on Failure Process of Rock Particle under Impact Loading
}

\author{
Yu-Jun Zuo, ${ }^{1,2,3,4}$ Qin Zhang, ${ }^{1,2,3,4}$ Tao Xu, ${ }^{5}$ Zhi-Hong Liu, ${ }^{1,2,3,4}$ \\ Yue-Qin Qiu, ${ }^{1,2,3,4}$ and Wan-Cheng $\mathrm{Zhu}^{5}$ \\ ${ }^{1}$ Mining College, Guizhou University, Guiyang, Guizhou 550025, China \\ ${ }^{2}$ Guizhou Key Laboratory of Comprehensive Utilization of Non-Metallic Mineral Resources, Guizhou University, \\ Guiyang, Guizhou 550025, China \\ ${ }^{3}$ Guizhou Engineering Lab of Mineral Resources, Guiyang, Guizhou 550025, China \\ ${ }^{4}$ Engineering Center for Safe Mining Technology under Complex Geologic Condition, Guiyang, Guizhou 550025, China \\ ${ }^{5}$ School of Resources \& Civil Engineering, Northeastern University, Shenyang, Liaoning 110004, China
}

Correspondence should be addressed to Qin Zhang; zq6736@163.com

Received 14 July 2014; Accepted 28 September 2014

Academic Editor: Caiping Lu

Copyright ( 2015 Yu-Jun Zuo et al. This is an open access article distributed under the Creative Commons Attribution License, which permits unrestricted use, distribution, and reproduction in any medium, provided the original work is properly cited.

By using numerical code $\mathrm{RFPA}^{2 \mathrm{D}}$ (dynamic version), numerical model is built to investigate the failure process of rock particle under impact loading, and the influence of different impact loading on crushing effect and consumed energy of rock particle sample is analyzed. Numerical results indicate that crushing effect is good when the stress wave amplitude is close to the dynamic strength of rock; it is difficult for rock particle to be broken under too low stress wave amplitude; on the other hand, when stress wave amplitude is too high, excessive fine particle is produced, and crushing effect is not very good on the whole, and more crushing energy is consumed. Secondly, in order to obtain good crushing effect, it should be avoided that wavelength of impact load be too short. Therefore, it is inappropriate to choose impact rusher with too high power and too fast impact frequency for ore particle.

\section{Introduction}

The purpose of crushing is to reduce the particle size of rock materials or to liberate valuable minerals from ores. In order to obtain higher efficiency of crushing, it is very important to select the appropriate crusher and crushing circuit. Research shows that the breakage of a brittle material is a very complex process, in which the results are influenced by loading conditions and the rock properties [1]. First of all, breakage of particles can be either single particle or interparticle [2]. The breakage behavior of single particle without constraint and stressing a large number of particles are not fully identical, because loading conditions on the surface of particles can be more complicated when stressing a large number of particles [3]. For this reason, when studying particle breakage behavior, single particle breakage conditions need to be adequately considered. If single particle is suffering loading from other adjacent particles, constraint condition in particle beds should be taken into consideration. What is more, the particle can not only be crushed under static loading but also be broken under dynamic loading. Therefore, particle breakage will require consideration of material properties, particle shape, and particle size. With such complex requirements, it is unlikely that any analytical approach would be adequate. The use of computer simulations seems to be the appropriate tool to obtain some clarification [4]. If we can get the rock crushing mechanism, according to numerical tests, and design or choose different crusher to control crushing effect, then technological process of coarse crushing and fine crushing can be optimized.

So far, it is seldom to investigate the mechanism on particle crushing from point of mechanical analysis. Traditionally, the breakage of material in crushing is regarded as relying upon single particle breakage without considering the confinement condition, and the physical point of departure is the Griffith theory of brittle fracture. The understanding of this 
breakage behaviour of a particle is based on the knowledge obtained in indirect tensile strength tests of rock, such as the Brazilian test or compression of an irregular specimen [5]. As for the breakage of material subjected to dynamic loading, researchers mainly focused on damage mechanism, fracture process, and dynamic fracture criterion of various materials in the past few decades [6]. Besides, the relationship between parameters such as modulus of elasticity, strength, and deformation rate is elucidated; therefore strength criterion and constitutive relation of rock particles are summarized under dynamic loading [7-9]. The finite element method and the finite difference method based on the traditional continuum mechanics are suitable for prediction of damages and failure, but they are difficult to be used for calculation and simulation of the complete failure process directly. Based on mesoscopic damage mechanics, numerical code $\mathrm{RFPA}^{2 \mathrm{D}}$ (dynamic version) is developed by Tang and Kou $[2,10]$ to simulate the failure process of a single particle breakage and interparticle breakage subjected to an unconfined or confined static compressive load, which provides a reasonable description of fundamental mechanisms of particles breakage. In fact, particle breakage is usually subjected to dynamic loading. In order to study the damage and breakage mechanism of rock particles under dynamic loading, $\mathrm{RFPA}^{2 \mathrm{D}}$ (dynamic version) was used to study dynamic fragmentation of rock, and the effect of loading rate on failure characteristics was discussed sketchily [11].

In this paper, by using numerical code $\mathrm{RFPA}^{2 \mathrm{D}}$ (dynamic version), the failure process of ore particle under impact loading is simulated, and the influence of different impact loading on crushing effect and consumed energy of ore particle sample is analyzed.

\section{Numerical Simulator Description}

The newly developed RFPA ${ }^{2 \mathrm{D}}$ (dynamic edition) is a twodimensional code that can simulate the fracture and failure process of rock under static or dynamic loading conditions. To model the failure of rock material or rock mass, the rock medium is assumed to be composed of many mesoscopic elements whose material properties are different from one to another and are specified according to a Weibull distribution [12]. The finite element method is employed to obtain the stress fields in the mesoscopic elements. Elastic damage mechanics is used to describe the constitutive law of the mesoscale elements when the maximum tensile strain criterion and the Mohr-Coulomb criterion that incorporate the effect of stress rate are utilized as damage thresholds [13].

2.1. Assignment of Material Properties. In RFPA, the solid or structure is assumed to be composed of many mesoscopic elements with the same size, and the mechanical properties of these elements are assumed to conform to a given Weibull distribution as defined by the following probability density function (PDF):

$$
f(u)=\frac{m}{u_{0}}\left(\frac{u}{u_{0}}\right)^{m-1} \exp \left[-\left(\frac{u}{u_{0}}\right)^{m}\right],
$$

where $u$ is the mechanical parameter of the element (such as strength or elastic modulus), the scale parameter $u_{0}$ is related to the average of the element parameters, and the parameter $m$ defines the shape of the distribution function. From the properties of the Weibull distribution, a larger value of $m$ implies a more homogeneous material and vice versa. Therefore, the parameter $m$ is called the homogeneity index in our numerical simulations. In the definition of the Weibull distribution, the value of the parameter $m$ must be larger than 1.0. Using the PDF, in a computer simulation of a medium composed of many mesoscopic elements, one can produce numerically a heterogeneous material. The computationally produced heterogeneous medium is analogous to a real specimen tested in the laboratory, so in this investigation it is referred to as a numerical specimen.

2.2. The Constitutive Model for the Mesoscopic Element. Initially an element is considered elastic, with elastic properties defined by Young's modulus and Poisson's ratio. The stressstrain relation for an element is considered linear elastic until the given damage threshold is attained and then is modified by softening. Under a dynamic stress state, the elements undergo damage when one of the following damage criteria is satisfied at the element level:

$$
-\varepsilon_{1}=\frac{k f_{c 0}}{E_{0}}, \quad \sigma_{1}-\frac{1+\sin \phi}{1-\sin \phi} \sigma_{3} \geq f_{c 0},
$$

where $f_{c 0}$ is the dynamic uniaxial compressive strength of the element, which is closely related to the strain rate (or stress rate) of dynamic loading condition, $E_{0}$ is initial elastic modulus of the element that is assumed to be not affected by the stress rate, $k$ is the ratio of compressive and tensile strength, and $\phi$ is the internal frictional angle of the element. $\sigma_{1}$ and $\sigma_{3}$ are the major and minor principal stresses of the element.

In this study, the following relation between dynamic uniaxial compressive strength and loading rate, which has been proposed by Zhao [7], is used to reflect the effect of stress loading rate on the dynamic strength:

$$
f_{c 0}=A \log \left(\frac{\dot{\sigma}}{\dot{f}_{c s o}}\right)+f_{c s o}, \quad \dot{\sigma}>\dot{f}_{c s o},
$$

where $f_{c 0}$ is also the dynamic uniaxial compressive strength $(\mathrm{MPa}), \dot{\sigma}$ is the stress rate $(\mathrm{MPa} / \mathrm{s}), f_{c s o}$ is the uniaxial compressive strength at the quasistatic stress rate $\dot{f}_{c s o}$ that is approximately $5 \times 10^{-2} \mathrm{MPa} / \mathrm{s}$, and $A$ is a parameter depending on the material. In addition, the experimental results of Zhao [7] also indicated that the ratio of tensile and compressive strength $\left(k=f_{c 0} / f_{t 0}\right)$ and internal frictional angle $\phi$ are not influenced by the stress rate. In this respect, when the $f_{c 0}$ obtained from (3) is substituted into (2), the effect of strain rate on the strength of elements will be incorporated.

The first part of (2) is the maximum tensile strain criterion, whilst the second part is the classical Mohr-Coulomb failure criterion for tensile and shear damage thresholds, respectively. Thus, an element may be damaged in either tension (corresponding to the maximum tensile strain criterion) 


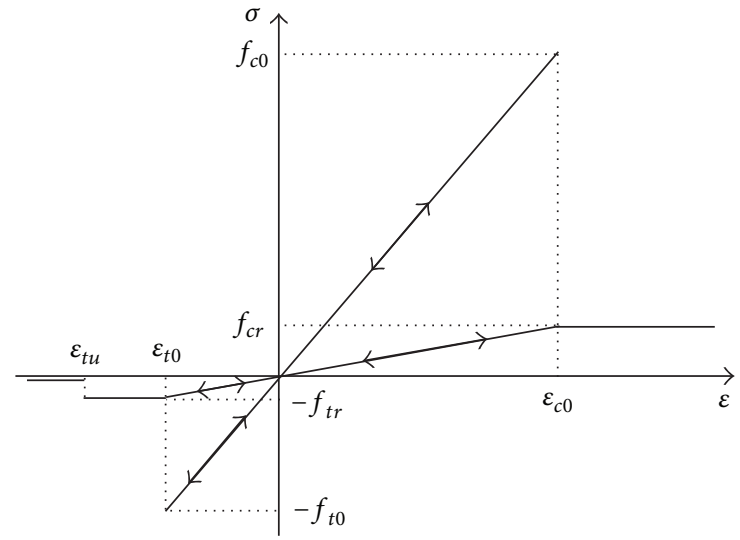

FIGURE 1: Elastic damage constitutive law of element under uniaxial stress state. (Here $f_{t 0}$ and $f_{t r}$ are dynamic uniaxial tensile strength and residual uniaxial tensile strength of element, respectively. And $f_{c 0}$ and $f_{c r}$ are dynamic uniaxial compressive strength and residual corresponding strength of element, resp.)

or shear (corresponding to the Mohr-Coulomb criterion). Once (2) is satisfied at the element level, the elastic modulus of the element is reduced according to the following expression:

$$
E=(1-\omega) E_{0}
$$

where $\omega$ represents a damage variable, $E$ and $E_{0}$ are the elastic modulus of the damaged and the undamaged element, respectively. In the current method, the element and its damage are assumed isotropic, so the $E, E_{0}$, and $\omega$ are all scalar quantities. The sign convention used throughout this paper is that compressive stress and strain are positive.

When the mesoscopic element is in a uniaxial stress state (both uniaxial compression and uniaxial tension), the constitutive relation of elements is as illustrated in Figure 1. Initially, the stress-strain curve is linear elastic and no damage exists; that is, $\omega=0$. When the maximum tensile strain criterion is satisfied, damage occurs in the element in a brittle mode.

The constitutive relation of the mesoscopic element under uniaxial tension, as shown in the third quartile of Figure 1, can be expressed as

$$
\omega= \begin{cases}0, & \varepsilon>\varepsilon_{t 0}, \\ 1-\frac{\lambda \varepsilon_{t 0}}{\varepsilon}, & \varepsilon_{t u}<\varepsilon \leq \varepsilon_{t 0}, \\ 1, & \varepsilon \leq \varepsilon_{t u},\end{cases}
$$

where $\lambda$ is the residual strength coefficient, which is given as $f_{t r}=\lambda f_{t 0}$, and $f_{t 0}$ is the tensile strength of element. The parameter $\varepsilon_{t 0}$ is the strain at the elastic limit, which is called the threshold strain, and is calculated as

$$
\varepsilon_{t 0}=-\frac{f_{t 0}}{E_{0}} .
$$

From (6), it can be found that $\varepsilon_{t 0}$ also depends on the stress rate of element because $f_{c 0}$ is related to the stress rate according to (3). $\varepsilon_{t u}$ is the ultimate tensile strain of the element, describing the state at which the element would be completely damaged. The ultimate tensile strain is defined as $\varepsilon_{t u}=\eta \varepsilon_{t 0}$, where $\eta$ is called the ultimate strain coefficient. Both the residual strength coefficient $(\lambda)$ and ultimate strain coefficient $(\eta)$ are assumed to be independent of the stress rate.

Additionally, it is assumed that the damage of a mesoscopic element under multiaxial states of stress is also isotropic and elastic. The constitutive equation described above can be extended for application to 3D stress states when the tensile strain threshold is attained. In multiaxial stress states, the element is still subject to damage in the tensile mode when the equivalent major tensile strain $\bar{\varepsilon}$ attains the above threshold strain $\varepsilon_{\mathrm{t} 0}$. The equivalent principal strain $\bar{\varepsilon}$ is defined by

$$
\bar{\varepsilon}=-\sqrt{\left\langle-\varepsilon_{1}\right\rangle^{2}+\left\langle\varepsilon_{2}\right\rangle^{2}+\left\langle\varepsilon_{3}\right\rangle^{2}}
$$

where $\varepsilon_{1}, \varepsilon_{2}$, and $\varepsilon_{3}$ are three principal strains and \langle\rangle is a function defined as follows:

$$
\langle x\rangle= \begin{cases}x, & x \geq 0 \\ 0, & x<0\end{cases}
$$

For an element subject to a multiaxial state of stress, the constitutive law can be easily obtained by substituting the strain $\varepsilon$ in (5) with the equivalent strain $\bar{\varepsilon}$ defined by (7) and (8). The damage variable is expressed as

$$
\omega= \begin{cases}0, & \bar{\varepsilon}>\varepsilon_{t 0}, \\ 1-\frac{\lambda \varepsilon_{t 0}}{\varepsilon}, & \varepsilon_{t u}<\bar{\varepsilon} \leq \varepsilon_{t 0}, \\ 1, & \bar{\varepsilon} \leq \varepsilon_{t u} .\end{cases}
$$

In the same way as for uniaxial tension, when the element is under uniaxial compression but damaged according to the Mohr-Coulomb criterion, the expression for damage variable $\omega$ can be described as

$$
\omega= \begin{cases}0, & \varepsilon<\varepsilon_{c 0}, \\ 1-\frac{\lambda \varepsilon_{c 0}}{\varepsilon}, & \varepsilon \geq \varepsilon_{c 0}\end{cases}
$$

$\lambda$ is also the residual strength coefficient, and $f_{c r} / f_{c 0}=$ $f_{t r} / f_{t 0}=\lambda$ is assumed to apply when the element is under either uniaxial compression or tension. Also, $\varepsilon_{c 0}$ is calculated as

$$
\varepsilon_{c 0}=\frac{f_{c 0}}{E_{0}}
$$

If an element is under a multiaxial stress state and its strength satisfies the Mohr-Coulomb criterion, damage occurs, and it is necessary to consider the effect of the other principal stress in the model during damage evolution. When the Mohr-Coulomb criterion is satisfied, the maximum principal (compressive) strain $\varepsilon_{c 0}$ can be calculated at the peak value of the maximum principal (compressive) stress:

$$
\varepsilon_{c 0}=\frac{1}{E_{0}}\left[f_{c 0}+\frac{1+\sin \phi}{1-\sin \phi} \sigma_{3}-\mu\left(\sigma_{1}+\sigma_{2}\right)\right] .
$$


It is assumed that shear damage evolution is related only to the maximum compressive principal strain $\varepsilon_{1}$. So the maximum compressive principal strain $\varepsilon_{1}$ of the damaged element is substituted for the uniaxial compressive strain $\varepsilon$ in (10), extending the equation to represent shear damage under triaxial stress states:

$$
\omega= \begin{cases}0, & \varepsilon_{1}<\varepsilon_{c 0}, \\ 1-\frac{\lambda \varepsilon_{c 0}}{\varepsilon_{1}}, & \varepsilon_{1} \geq \varepsilon_{c 0} .\end{cases}
$$

Based on the above equations, it can be found that the damage variable $\omega$ is related to the stress rate because it is calculated based on the values of $\varepsilon_{c 0}$ or $\varepsilon_{t 0}$ that are obtained directly according to the stress-rate dependent strength of the element $\left(f_{c 0}\right.$ or $\left.f_{t 0}\right)$ according to (6) or (11).

Of course, the above-mentioned constitutive law can be used to simulate the failure process of rock under static loading when the stress rate effect on the strength as expressed by (3) is not incorporated. Therefore, the stress-rate dependent constitutive law described above is based on the original one for static analysis and is also compatible with it.

2.3. Finite Element Implementation. As described above, the rock specimen is composed of many square elements with the same size. These elements are also acting as the four node parameter elements for finite element analysis. The equilibrium equations governing the linear dynamic response of a system of finite elements can be expressed in the following form:

$$
M \ddot{U}+C \dot{U}+K U=R,
$$

where $M, C$, and $K$ are the mass, damping, and stiffness matrices; $R$ is the vector of externally applied loads; and $U, \dot{U}$, and $\ddot{U}$ are the displacement, velocity, and acceleration vectors of the finite elements. A direct step-by-step integration procedure is found suitable for solving the problem in which a body is subjected to a short duration impulse loading [14].

At initial condition, the elements are elastic, and their stresses can be calculated via step-by-step integration. At a time step, the principal stresses from the previous time step are subtracted from the current principal stresses and divided by the time step in order to calculate the stress rates of the elements. Similarly, when the current minor principal stress and corresponding stress rate are both negative, the increased strength of an element due to the increase of absolute value of this stress rate can also be obtained. When the effect of stress rate on the dynamic compressive strength is considered according to (3) and the stresses (or strains) of elements meet the maximum tensile strain criterion or Mohr-Coulomb criterion as given in (2), the elements are damaged according to the constitutive law given before, and then their stress will be reanalyzed iteratively for the current boundary conditions in order to reflect the stress redistribution at this time step. The program does not consider the analysis of the next time step until no new damaged elements are found for the iterative step of this time step. The above model described in the two preceding sections is implemented into the RFPA $[15,16]$, and therefore RFPA is extended for analysis of rock under dynamic loading.

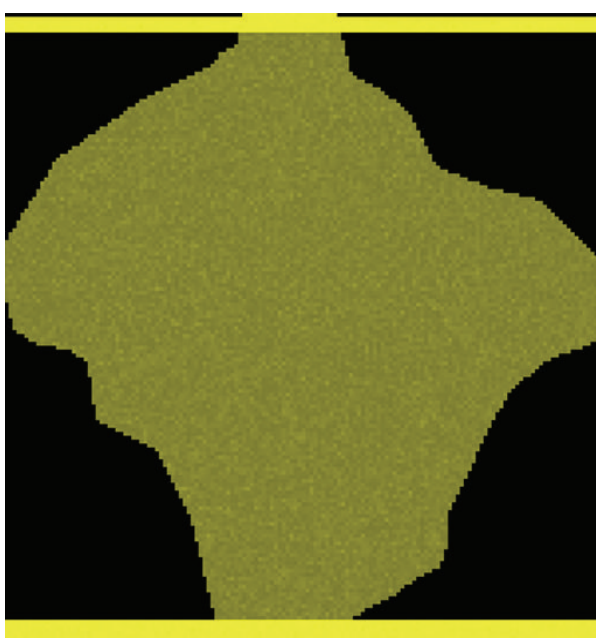

FIGURE 2: The numerical sample model of ore (generated by RFPA).

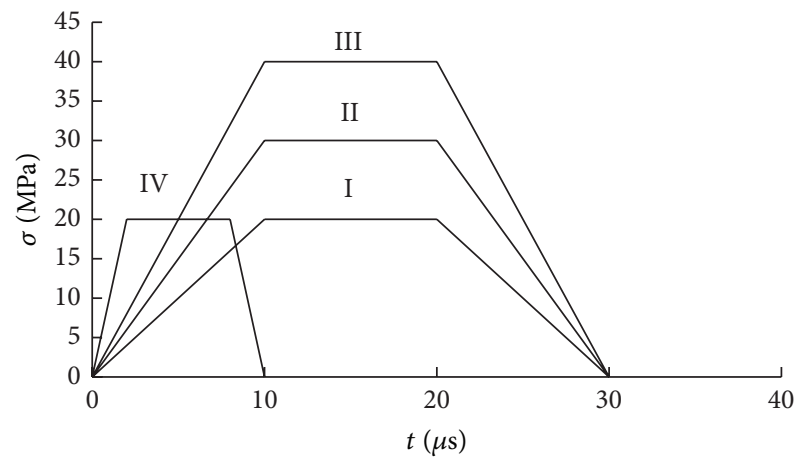

FIGURE 3: Different stress waves exerted on samples.

\section{Numerical Model}

Research object is sample of ore particle, and the numerical sample model built with rock failure process analysis system RFPA is shown in Figure 2, which is $150 \mathrm{~mm}$ high and $150 \mathrm{~mm}$ wide. Loading plate, which is $5 \mathrm{~mm}$ thick, is uniform and elastic, and its elastic modulus is $200 \mathrm{GPa}$, and Poisson ratio is 0.25 . The mechanical parameters of above-mentioned sample are close to phosphate. Moreover, assume that the mechanical property of the mesoscopic unit, which composes ore sample, is in accordance with Weibull distribution, and the mechanical property of the numerical sample is shown in Table 1 .

In the process of dynamic loading, an impulsive load pulse is exerted on the loading plate of the sample. The pulse varies over time, which can be seen from Figure 3. On one hand, stress wave is exerted according to the three circumstances shown in segment I to segment III in Figure 3. In order to research the effect of amplitude on the failure model, three stress waves act on the sample. The wave crests are $\sigma_{\max }=20 \mathrm{MPa}, 30 \mathrm{MPa}$, and $40 \mathrm{MPa}$, respectively. On the other hand, in order to investigate the effect of different wavelength on the failure model of the sample, stress waves are loaded according to I and IV shown in Figure 3. 
TABLE 1: The mechanical property of the sample of ore particle.

\begin{tabular}{|c|c|c|c|c|c|c|c|}
\hline \multicolumn{2}{|c|}{$\begin{array}{l}\text { The average value of } \\
\text { elasticity modulus/GPa }\end{array}$} & $\begin{array}{l}\text { The averag } \\
\text { uniaxial co } \\
\text { strength }\end{array}$ & $\begin{array}{l}\text { e value of } \\
\text { mpressive } \\
\mathrm{MPa}\end{array}$ & \multirow[t]{2}{*}{ Poisson's ratio } & \multirow{2}{*}{$\begin{array}{l}\text { The ratio of the } \\
\text { compressive strength } \\
\text { to tensile strength }\end{array}$} & \multirow[t]{2}{*}{$\begin{array}{c}\text { Volume } \\
\text { mass } / \mathrm{kg} / \mathrm{cm}^{3}\end{array}$} & \multirow[t]{2}{*}{$\begin{array}{l}\text { Homogeneity } \\
\text { index }\end{array}$} \\
\hline Macroscopy & Mesoscopy & Macroscopy & Mesoscopy & & & & \\
\hline 15 & 19 & 30 & 97 & 0.25 & 10 & 2.8 & 3 \\
\hline
\end{tabular}

TABLE 2: Fracturing process of sample under stress waves with different amplitude.

Amplitude of stress wave,

There are two loading boundary conditions. (1) Bottom is fixed, both sides are free, and an impulsive load pulse is exerted on the area with specific width. This loading boundary condition is settled in order to discuss the failure behaviour of the particle under the condition of lateral freedom. (2) Both bottom and lateral are fixed, and an impulsive load pulse is exerted on the area with specific width. This loading boundary condition is settled for discussing the failure behaviour of the particle under constraint condition.

\section{The Result and Analysis of the Numerical Simulation}

\subsection{The Effect of Different Dynamic Stress Wave Amplitudes}

4.1.1. The Failure Process Analysis of Ore Samples. In numerical simulation, loading stress waves of which amplitude $\sigma_{\max }$ is $20 \mathrm{MPa}, 30 \mathrm{MPa}$, and $40 \mathrm{MPa}$, respectively, are adopted. Due to limitation of page, only the fracture processes for the shear stress field of the time steps are used, as shown in Table 2. Here, only some groups of typical simulated result maps are selected, which reflect the failure status of the sample at $20 \mu \mathrm{s}, 60 \mu \mathrm{s}$, and $80 \mu \mathrm{s}$, respectively. In the following figure of stress distributions, the gray degree denotes corresponding magnitude of element shear stress, that is, the brighter the point, the greater the shear stress of the element, and the black points indicate failure of elements. Table 2 shows the different failure processes of sample under different loading step.

When value of the exerted stress wave crest is at lower levels, such as wave crest $\sigma_{\max }=20 \mathrm{MPa}$, the value of the stress wave crest is less than the dynamic compressive strength of the ore. After the stress wave passes loading plate onto the top of the particle, it is not enough to crush ore into pieces. Therefore, the part of ore that touches loading plate is not destroyed, for example, when the propagation time $t=20 \mu \mathrm{s}$. When stress waves continue to propagate downward, stress wave reflection occurs as the stress wave reaches both sides of the particle. At this moment tensile fracture in particle is caused. As a result, tensile fracture area will be generated when stress waves arrive in the area. Stress wave attenuates rapidly when stress waves continue to propagate downward. Therefore, before stress wave propagates to the free surface below the particle, there is less elements fracture, shown in figure of propagation time $t=60 \mu \mathrm{s}$. So, when stress wave propagates to the free surface below the particle, extension wave is generated. When the amplitude of the extension wave is bigger than tensile strength of the ore element, tensile fracture is generated in the element of particle. Consequently, 

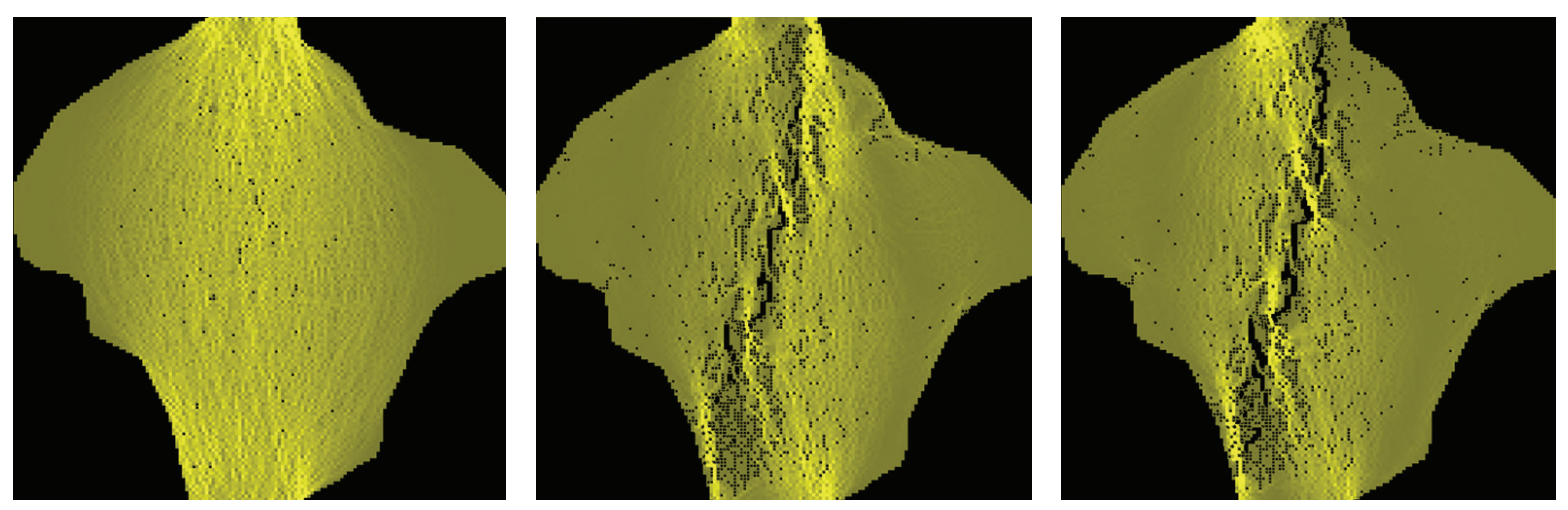

FIGURE 4: Maximum shear stress distribution map under static loading condition ((a)-(c) denote the order of rupture, and the stress unit is $\mathrm{MPa})$.

a few number of elements will fracture near the bottom of particle, and when more failure elements occur, macroscopic tensile cracks may be generated, as shown in failure process at $t=80 \mu \mathrm{s}$. Comparing dynamic fracture model with fracture model under static loading, a principal crack runs through direction of the height of the samples under static loading, as shown in Figure 4; more cracks will be caused in the sample under dynamic loading, and more cracks coalesce into macroscopic cracks in the sample.

When value of the exerted stress wave crest increases to $\sigma_{\max }=30 \mathrm{MPa}$, the value of the stress wave crest is close to dynamic compressive strength of the ore. After the stress wave passes loading plate onto the top of the particle, the particle elements with lower strength which contact loading plate will be crushed, for example, when the propagation time $t=20 \mu \mathrm{s}$. When stress waves continue to propagate downward, stress wave reflection occurs as the stress wave reaches both sides of the particle. With the combined action of reflected wave and compressive stress wave, at this moment, tensile and crash fracture in particle are caused. As a result, obvious tensile fracture area will be generated when stress waves arrive in the area. Stress wave attenuates rapidly when stress waves continue to propagate downward. Therefore, before stress wave propagates to the free surface below the particle, there is also less elements fracture, shown in figure of propagation time $t=60 \mu \mathrm{s}$. When stress wave propagates to the free surface below the particle, extension wave is generated. At this moment the amplitude of the extension wave is bigger than amplitude of the stress wave $\sigma_{\max }=20 \mathrm{MPa}$. Consequently, there are also lots of fracture elements produced near the bottom of particle, and more macroscopic tensile cracks may be generated, as shown in failure process at $t=80 \mu$ s period.

When value of the exerted stress wave crest increases to $\sigma_{\max }=40 \mathrm{MPa}$, the value of the stress wave crest is more than dynamic compressive strength of the ore. After the stress wave passes loading plate onto the top of the particle, the particle elements which contact loading plate will be crushed, for example, when the propagation time $t=20 \mu \mathrm{s}$. At this time, the ore is shattered with large energy consumption. When stress waves continue to propagate downward, stress wave reflection occurs as the stress wave reaches both sides

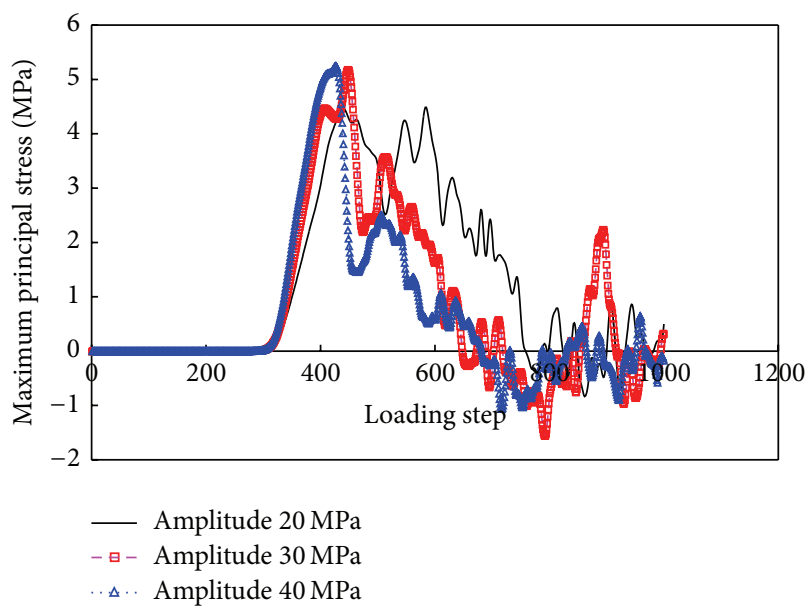

FIGURE 5: Variation law of maximum principle stress on numerical sample unit.

of the particle. With the combined action of reflected wave and compressive stress wave, at this moment, tensile and crash fracture in particle are caused. As a result, obvious tensile fracture area will be generated when stress waves arrive in the area. At this moment fracture area is larger than the two circumstances mentioned above. When stress wave continues to propagate downward until $(75,80)$, the variation law of stresses at this point is shown as in Figures 5,6 , and 7. Stress wave attenuates faster because stress wave consumes large amount of energy in crushing area before arriving at this point. Therefore, before stress wave propagates to the free surface below the particle, there is less elements fracture, shown in figure of propagation time $t=60 \mu \mathrm{s}$. When stress wave propagates to the free surface below the particle, extension wave is generated. At this moment the extension wave amplitude is less than the two stress waves' amplitude aforementioned. Consequently, a few number of elements will fracture near the bottom of particle, and when more failure elements occur, macroscopic tensile cracks may be generated in part area, as shown in failure process at $t=80 \mu \mathrm{s}$ period. 


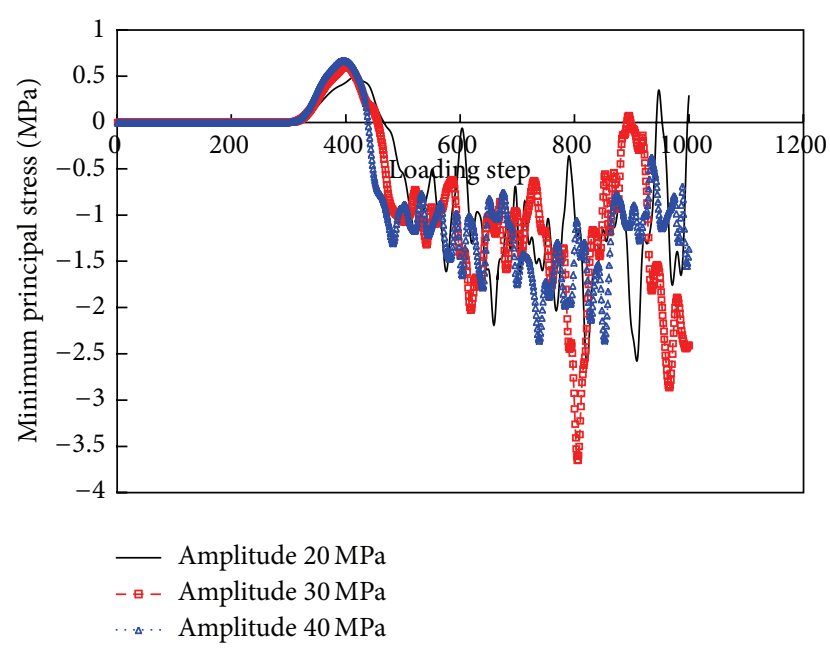

FIGURE 6: Variation law of minimum principle stress on numerical sample unit.

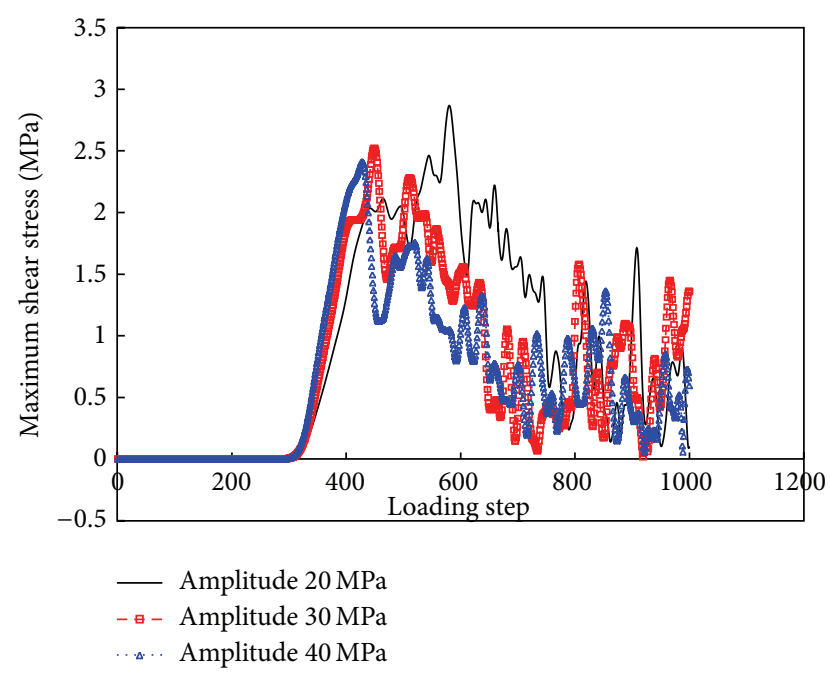

FIGURE 7: Variation law of maximum shear stress on numerical sample unit.

According to the above situation, it is better that the amplitude of stress wave be close to the dynamic strength of the ore subjected to impulsive loading; it is not enough to break the ore when amplitude of stress wave is too small. On the other hand, there will be more ore fines generated when the amplitude exceeds critical range, and crushing effect is generally not as good as desired.

\subsubsection{Statistical Analysis of Accumulated Counts of Damaged} Elements of Particle. When simulation sample is loaded with three stress waves with different amplitudes, there is a number of damaged elements occurrence in sample at two loading steps; for example, when $\sigma_{\max }=30 \mathrm{MPa}$, the loading steps (i.e., the propagation time is $30 \mu$ s and $70 \mu \mathrm{s}$, resp.) are numbers 300 and 700, respectively, as shown in Figure 8. Seen from failure process at different loading steps while a number of damaged elements occur, the less the stress wave amplitude

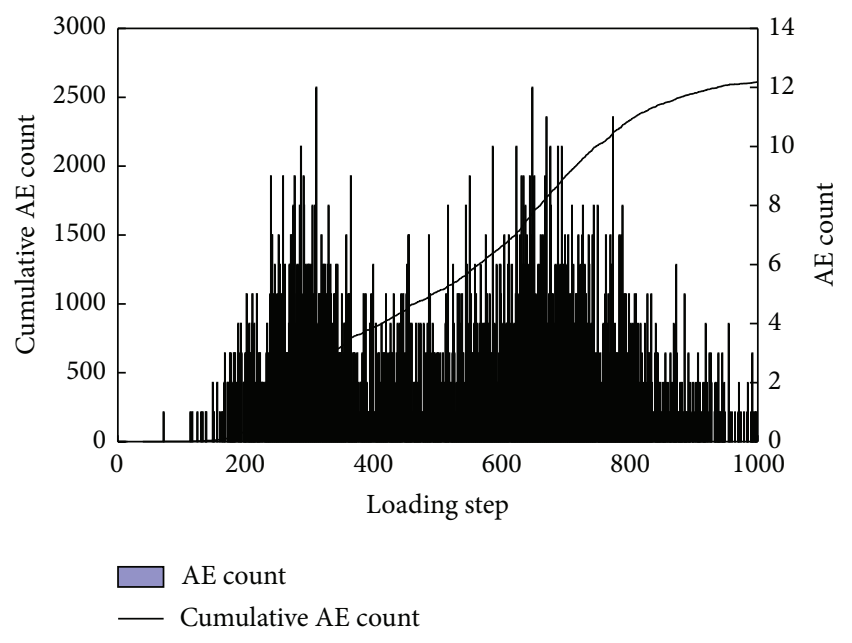

Figure 8: Accumulative damaged elements (AE) of sample in a different loading step $\left(\sigma_{\max }=30 \mathrm{MPa}\right)$.

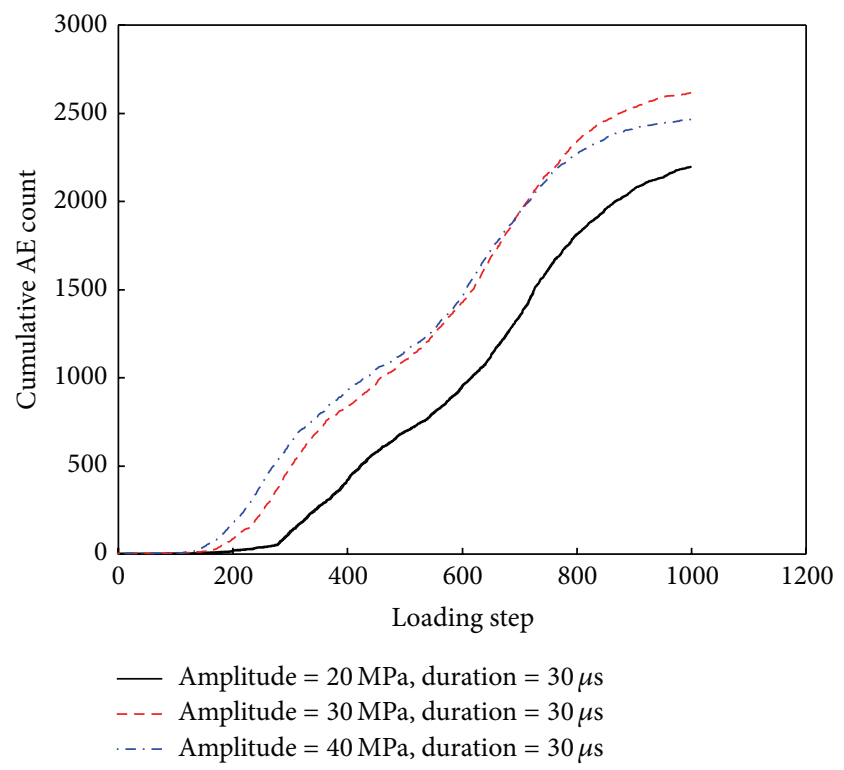

FIGURE 9: The variation of accumulated counts of AE under different stress wave amplitudes.

is, the later a number of damage elements failure occurs; the greater the stress wave amplitude is, the earlier a number of damage elements failure occurs.

When simulation sample is loaded with three stress waves with different amplitudes, the changing rule of accumulated counts of damaged elements of sample is shown in Figure 9. Seen from Figure 9, the less the stress wave amplitude, the less the accumulated counts of damaged elements of the sample at the same loading step; that is, the less the stress wave amplitude, the less cracks generated in sample; the greater the stress wave amplitude, the more the accumulated counts of damaged elements of the sample at the same loading step; that is, the greater the stress wave amplitude, the more cracks generated in the sample; however, if the stress wave amplitude is too high, the accumulated counts of damaged elements of 
TABLE 3: Failure process of the sample under different wavelengths (stress amplitude is $20 \mathrm{MPa}$ ).

Propagation time of stress wave, $t / \mu$ s

20

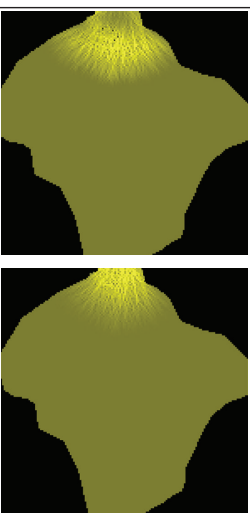

60

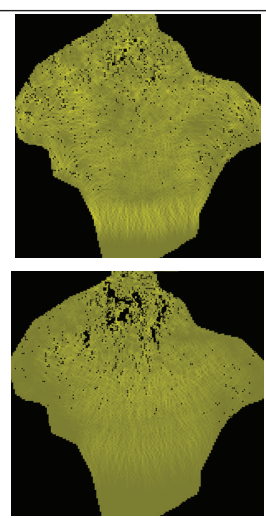

80

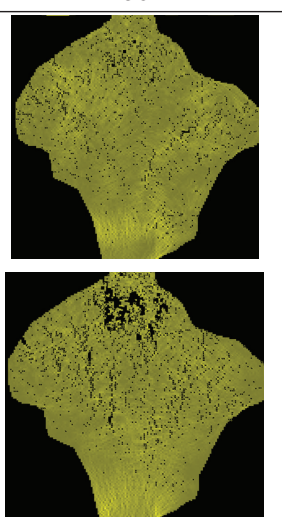

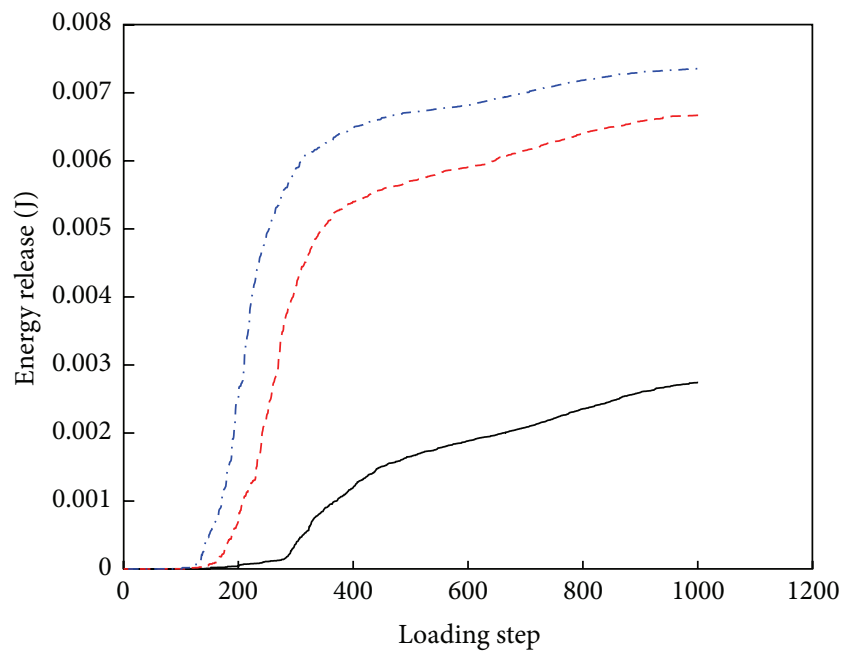

- Amplitude $=20 \mathrm{MPa}$, duration $=30 \mu \mathrm{s}$

--- Amplitude $=30 \mathrm{MPa}$, duration $=30 \mu \mathrm{s}$

-. - - Amplitude $=40 \mathrm{MPa}$, duration $=30 \mu \mathrm{s}$

FIGURE 10: Variation of energy release of damaged elements of particle under different stress wave amplitudes.

the sample at the same loading step do not increase at large, but accumulated counts increase a little while stress wave propagates at the top of the sample, and accumulated counts are less than that of the less stress wave amplitude while stress wave propagates at the bottom of the sample, which indicate that the crushing effect is worse if stress wave amplitude is too large. This is due to comminuting at the top which consumes a lot of energy, so then stress wave attenuates fast when stress wave amplitude is too large.

4.1.3. Analysis of Energy Release of Damaged Elements of Particle. When simulation sample is loaded with stress waves with different amplitudes, the changing rule of energy release of damaged elements of particle is shown in Figure 10. Seen from Figure 10, the more the stress wave amplitude is, the more the energy release of damaged elements of particle at the same loading step is. Analysis shows that the greater the stress wave amplitude, the more the energy consumption of damaged elements of particle.

Seen from the analysis results of the failure process of the sample under different stress wave amplitudes, it is better that the amplitude of stress wave be close to the dynamic strength of the ore subjected to impulsive loading; it is not enough to break the ore when amplitude of stress wave is too small. On the other hand, there will be more ore fines generated when the amplitude exceeds critical range, and crushing effect is generally not as good as desired. And if the stress amplitude is too large, not only desired crushing effect is not obtained, but also more energy in fragmentation is consumed. Therefore, too large power of crusher should not be selected for such ores.

\subsection{The Effect of Different Wavelength of Dynamic Stress}

4.2.1. Failure Process Analysis of Particles. When stress wave amplitude is $20 \mathrm{MPa}$ and wavelength is different, the failure process of the sample is shown in Table 3. Seen from Table 3, there is no big change in failure mode except for amount of damaged elements when wavelength is different. Less amount of damaged element occurs when the wavelength is short, that is, caused by less input of crushing energy as a result of short wavelength; when the wavelength is long, more amount of damaged elements occurs. Therefore, in order to get good crushing effect, the wavelength of impact load should not be too short; that is, the impact frequency of crusher for this kind of ore should not be too fast.

4.2.2. Statistical Analysis of Accumulated Counts of Damaged Elements of Ore Particle. When simulation sample is loaded with stress waves with different wavelength, seen from failure process at different loading steps while a number of damaged elements occur, the shorter the stress wavelength is, the earlier a number of damaged elements failure occurs; the longer the stress wave amplitude is, the later a number of damaged elements failure occurs. 


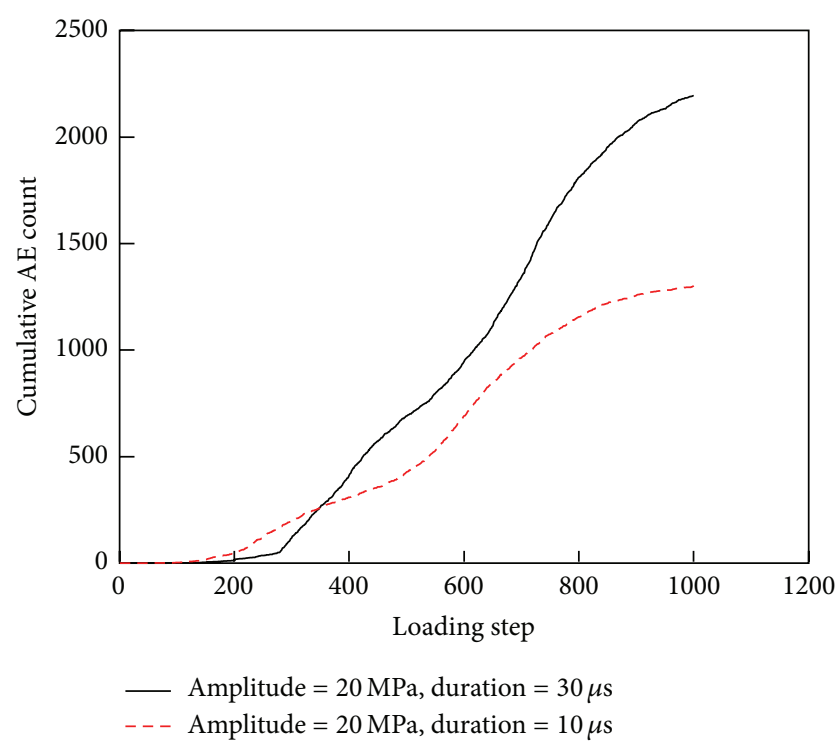

FIGURE 11: Variation of accumulated counts of failed elements (AE) of sample under different stress wavelength.

When simulation sample is loaded with stress waves with different wavelengths, the changing rule of accumulated counts of damaged elements of sample is shown in Figure 11. Seen from Figure 11, the shorter the stress wavelength is, the less the accumulated counts of damaged elements of sample at the same loading step (except for the beginning) are; that is, the shorter the stress wavelength, the less the cracks generated in the sample; the longer the stress wavelength, the more the accumulated counts of damaged elements of sample at the same loading step (except for the beginning); that is, the longer the stress wavelength, the more cracks generated in the sample. In the beginning of the stress wave propagation, accumulated counts of failed elements are relatively high while stress wave length is short. When the stress wave propagates to the border, stress wave reflection at free surface of boundary occurs, and because of the relatively short stress wavelength, more times of reflection occur and form more failed elements. This is consistent with aforementioned analysis results of a number of damaged elements occurring at some loading step. This fully indicates that there is a close relationship between the dynamic failure process and the stress wavelength.

4.2.3. Statistical Analysis of Energy Release of Damaged Elements of Particle. When simulation sample is loaded with stress waves with different wavelength, the changing rule of energy release of damaged elements of particle is shown in Figure 12. Seen from Figure 12, released energy in the failure process of sample increases with the increase of stress wavelength. It shows that more energy will be consumed for sample crushing with the increase of stress wavelength.

Seen from the analysis results of the failure process of the sample under different stress wavelength, in order to get good crushing effect, the wavelength of impact loads should not be

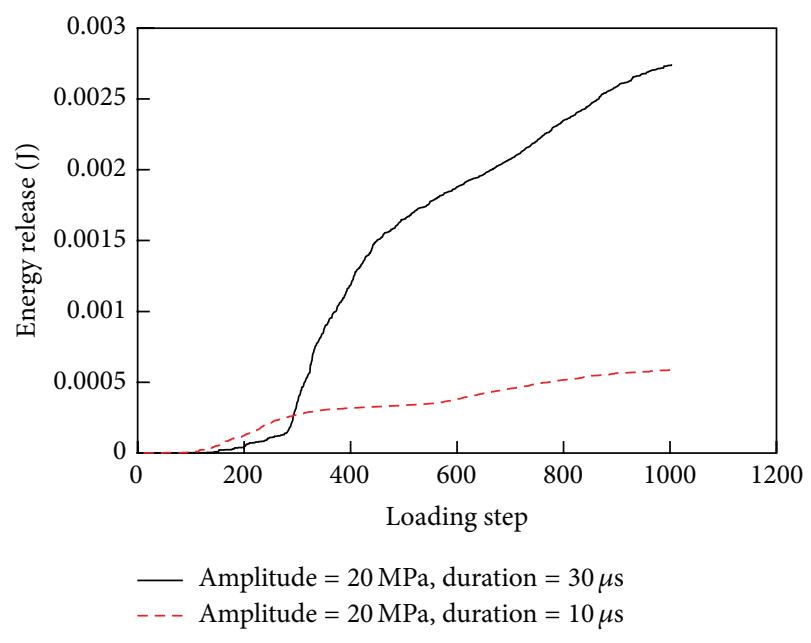

FIGURE 12: Variation of energy release of sample under different wavelength duration.

too short. Therefore, too high impact frequency of crushers should not be selected for such ores.

\subsection{The Influence of Lateral Constraint on Breakage of Ore Particle}

4.3.1. The Failure Process Analysis of Ore Particle. The breakage process of granular material, on which stress wave amplitude value is $20 \mathrm{MPa}$ and wavelength is $30 \mu \mathrm{s}$ and on both sides of which there is no constraint or constraint, is shown in Table 4. From Table 4, we know that the failure behavior of particle on both sides of which there is no constraint or constraint has nearly no change; only a small amount of change in the damage is extent. When there is no constraint on both sides of particle, the smaller the wavelength is, the larger the extent of damage is, but that is not obvious. This is rock-breaking effect using tensile stress wave under condition of no constraint. However, when there is constraint on both sides of particle, the extent of damage is lighter. So, in order to get the good effect of breakage, we need to consider the state of constraint of ore particle in the crushing chamber when we choose the proper crusher.

4.3.2. Statistical Analysis of Accumulated Counts of Damaged Elements of Ore Particle. When particle sample is constrained or unconstrained on both sides, damaged elements of ore particle at different loading step are shown in Figures 8 and 13. As shown in Figure 13, there are also obvious stages of elements damage of sample when the numerical sample is constrained but not sharper than that when it is unconstrained. When the numerical sample is constrained, the two times of a large number of damaged elements occurrence are $40 \mu \mathrm{s}$ and $75 \mu \mathrm{s}$, respectively. Compared with the two times of a large number of damaged elements occurrence ( $t=45 \mu \mathrm{s}$ and $t=75 \mu \mathrm{s}$ ) of numerical sample with unconstraint, the time is earlier than that when numerical sample is constrained. 
TABLE 4: The failure process of sample with no constraint and constraint.

No constraint

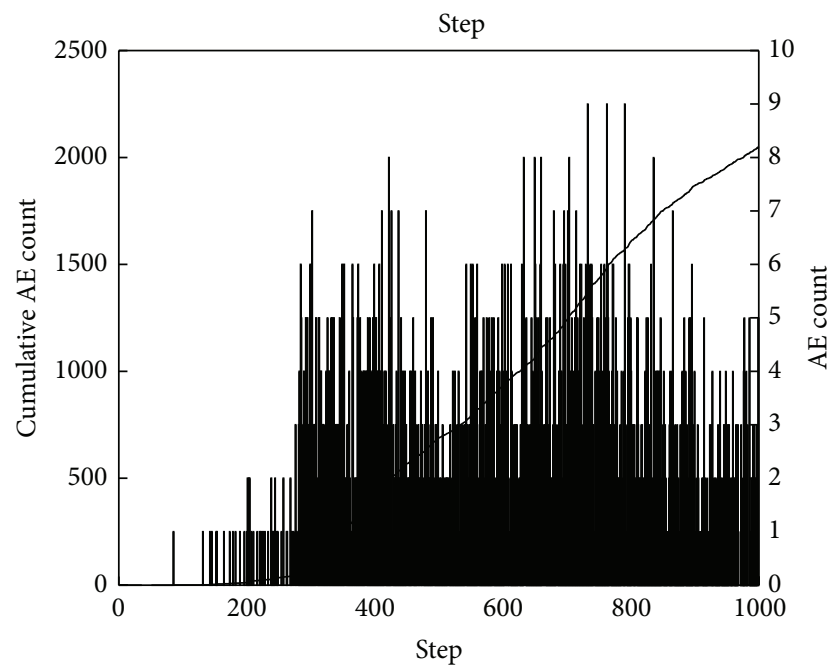

AE count

Cumulative AE count

FIGURE 13: The counts of damaged elements of numerical sample with constraint at different loading step.

Under different constraints, the change rules of accumulated counts of damaged elements are shown in Figure 14. From Figure 14, we can see that accumulated counts of damaged elements at the same propagation time in the initial stages are approached. But when the stress wave propagates to the bottom of particle, compared with that having constraint, the accumulated counts of damaged elements are larger than those having no constraint. This shows that the free surface of particle may have some effect on crushing of particle. We can use tensile stress wave generated by reflection of stress wave at free surface to fracture rock. It reflects that the dynamic breakage process has a certain relationship with the constraint of ore particle.

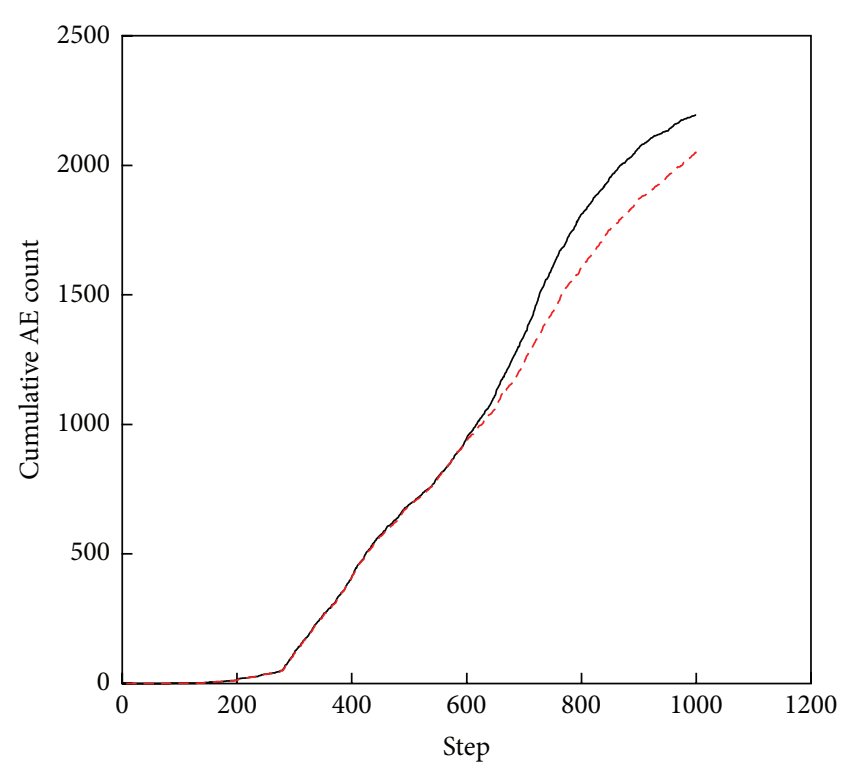

- Amplitude $=20 \mathrm{MPa}$, duration $=30 \mu$ s unconstraint

- - - Amplitude $=20 \mathrm{MPa}$, duration $=30 \mu$ s constraint

FIGURE 14: The accumulated counts of damaged elements of sample with unconstraint and constraint.

\subsubsection{Statistical Analysis of Energy Release of Damaged} Elements of Particle. When the two sides of sample have constraint or no constraint, the damage energy release change rule is shown in Figure 15. As shown in Figure 15, the damage energy release of numerical sample with unconstraint is smaller than that when it has constraint.

From the failure process analysis results of the numerical sample with unconstrained and constrained, we know that when impacting load crushing ore, in order to obtain good crushing effect, particles do not need constraints, but from the point of energy-efficient, the particle should carry on the constraint. 


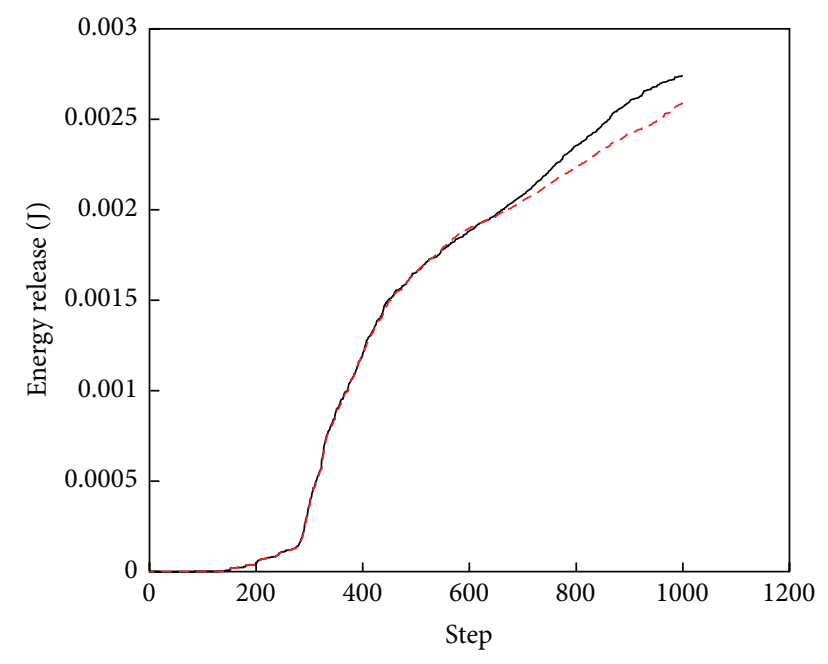

- Amplitude $=20 \mathrm{MPa}$, duration $=30 \mu$ s unconstraint

- - Amplitude $=20 \mathrm{MPa}$, duration $=30 \mu$ s constraint

FIGURE 15: The damage energy release change rule of sample with unconstraint and constraint.

\section{Conclusions}

In this paper, the dynamic rock failure process analysis (RFPA) code is used to analyze failure process of ore particles under impact loading. Numerical simulations show that it is better to break rock when the amplitude of stress wave is close to the dynamic strength of the ore subjected to impact loading; it is not enough to break the ore when stress wave amplitude is too small; on the other hand, there will be more ore fines generated when the stress amplitude exceeds critical range, and crushing effect is generally not as good as desired. And if the stress amplitude is too large, not only desired crushing effect is not obtained, but also more energy in fragmentation is consumed. Therefore, too large power of crusher should not be selected for such ores. In order to get good crushing effect, the wavelength of impact loads should not be too short. Therefore, too high impact frequency of crushers should not be selected for such ores. It should be noted that the effect of geometry shape changes and homogeneity of the actual ore particles on failure process requires to be studied further more. In addition, the physical tests of the mineral particles are still in progress.

\section{Conflict of Interests}

The authors declare that there is no conflict of interests regarding the publication of this paper.

\section{Acknowledgments}

The study presented in this paper was jointly funded by the National Technology R\&D Program for the 12th fiveyear plan (no. 2012BAB08B06), the National Natural Science Foundation of China (nos. 51164005, 51264005, 41172265, and 50874024), Project (GY(2011)3063) supported by Guizhou
Province Industry Tackles Key Problem Program, the Key Project for the Nature Science Research from the Guizhou Province Bureau of Education (2010003), the Governor Fund Project for Outstanding Scientific and Technological Education Talent from the Guizhou Province (2011-36), Special Project for Guizhou Province High-Level Personnel Scientific Research (TZJF-2010-044), and the Introducing Talents Project of Guizhou University (2010-008).

\section{References}

[1] C. M. Evertsson, Cone crusher performance [Ph.D. thesis], Chalmers University of Technology, Gothenburg, Sweden, 2000.

[2] C. A. Tang, X. H. Xu, S. Q. Kou, P.-A. Lindqvist, and H. Y. Liu, "Numerical investigation of particle breakage as applied to mechanical crushing - part I: single-particle breakage," International Journal of Rock Mechanics and Mining Sciences, vol. 38, no. 8, pp. 1147-1162, 2001.

[3] C. L. Prasher, Crushing and Grinding Process Handbook, John Wiley \& Sons, New York, NY, USA, 1987.

[4] O. Tsoungui, D. Vallet, and J.-C. Charmet, "Numerical model of crushing of grains inside two-dimensional granular materials," Powder Technology, vol. 105, no. 1-3, pp. 190-198, 1999.

[5] V. S. Vutukri, R. D. Lama, and S. S. Saluja, Handbook on Mechanical Properties of Rocks, Trans Technical Publications, Rockport, Mass, USA, 1974.

[6] Y.-J. Zuo, W.-C. Zhu, C.-A. Tang, X.-B. Li, and W.-H. Wang, "Numerical simulation on spallation process of inhomogeneous medium induced by reflection of stress wave," Journal of Central South University (Science and Technology), vol. 37, no. 6, pp. 1177-1182, 2006.

[7] J. Zhao, "Applicability of Mohr-Coulomb and Hoek-Brown strength criteria to the dynamic strength of brittle rock," International Journal of Rock Mechanics and Mining Sciences, vol. 37, no. 7, pp. 1115-1121, 2000.

[8] W.-X. Gao, J. Yang, and F.-L. Huang, "The constitutive relation of rock under strong impact loading," Transaction of Beijing Institute of Technology, vol. 20, no. 2, pp. 165-170, 2000 (Chinese).

[9] Y. Bin, L. Dianshu, Q. He et al., "Experimental study of granite's constitutive relation under blasting load," Journal of China University of Mining and Technology, vol. 28, no. 6, pp. 552-555, 1999 (Chinese).

[10] S. Q. Kou, H. Y. Liu, P. A. Lindqvist, C. A. Tang, and X. H. $\mathrm{Xu}$, "Numerical investigation of particle breakage as applied to mechanical crushing. Part II. Interparticle breakage," International Journal of Rock Mechanics and Mining Sciences, vol. 38, no. 8, pp. 1163-1172, 2001.

[11] Z.-P. Huang, W.-C. Zhu, C.-A. Tang, and L.-X. Li, "Numerical simulation on breakage of rock particles under dynamic loading," Journal of Shenyang Jianzhu University, vol. 22, no. 1, pp. 91-95, 2006 (Chinese).

[12] W. A. Weibull, "Statistical distribution function of wide applicability," Journal of Applied Mechanics, vol. 18, pp. 293-297, 1951.

[13] W. C. Zhu and C. A. Tang, "Micromechanical model for simulating the fracture process of rock," Rock Mechanics and Rock Engineering, vol. 37, no. 1, pp. 25-56, 2004.

[14] J. W. Tedesco, C. A. Ross, P. B. McGill, and B. P. O’Neil, "Numerical analysis of high strain rate concrete direct tension tests," Computers and Structures, vol. 40, no. 2, pp. 313-327, 1991. 
[15] C. A. Tang, "Numerical simulation of progressive rock failure and associated seismicity," International Journal of Rock Mechanics and Mining Sciences \& Geomechanics Abstracts, vol. 34, no. 2, pp. 249-261, 1997.

[16] C. A. Tang, H. Liu, P. K. K. Lee, Y. Tsui, and L. G. Tham, "Numerical studies of the influence of microstructure on rock failure in uniaxial compression-part I: effect of heterogeneity," International Journal of Rock Mechanics and Mining Sciences, vol. 37, no. 4, pp. 555-569, 2000. 

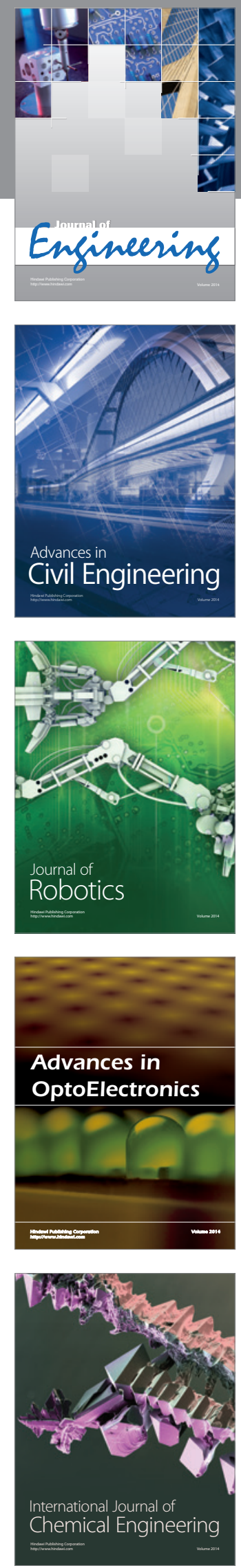

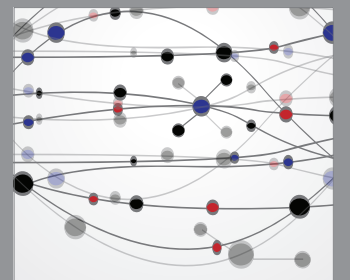

The Scientific World Journal
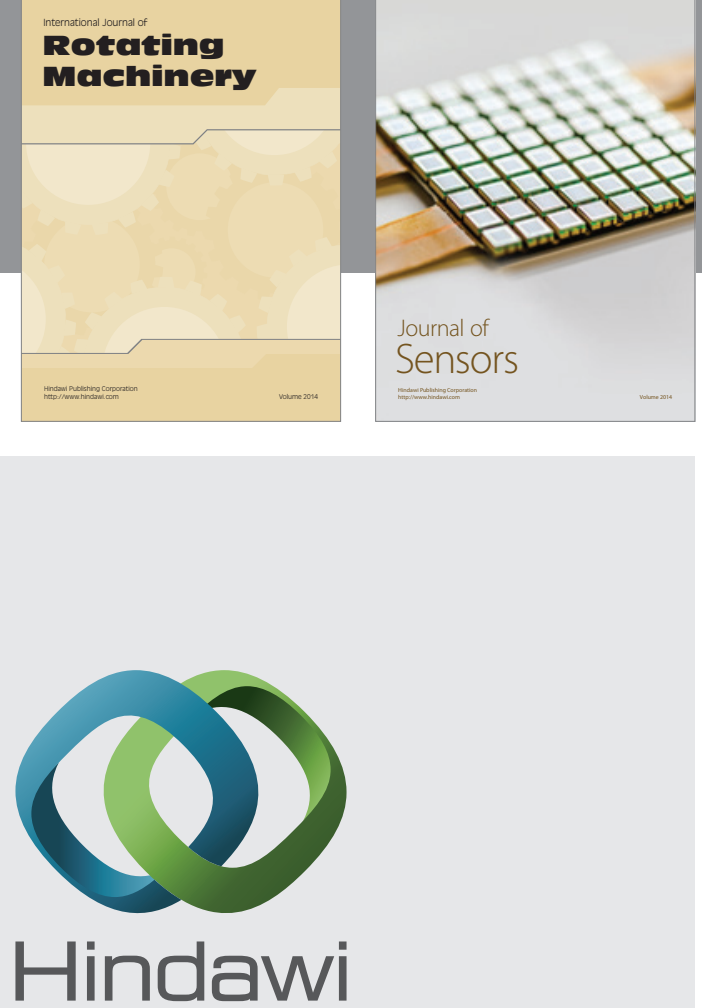

Submit your manuscripts at http://www.hindawi.com
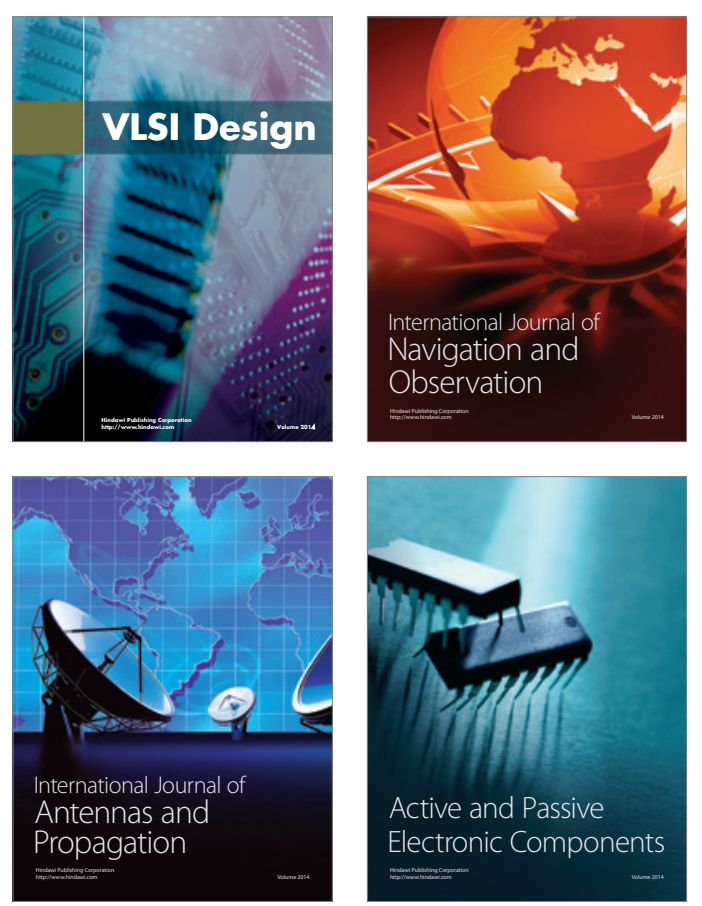
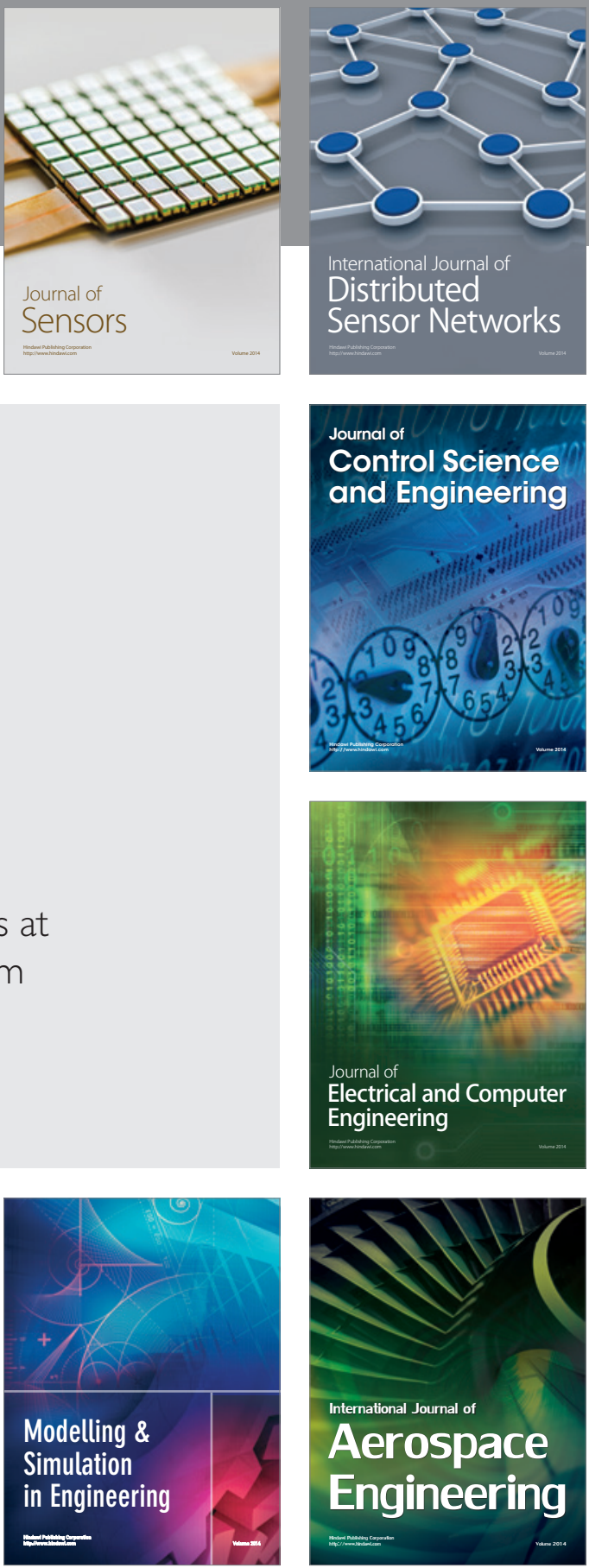

Journal of

Control Science

and Engineering
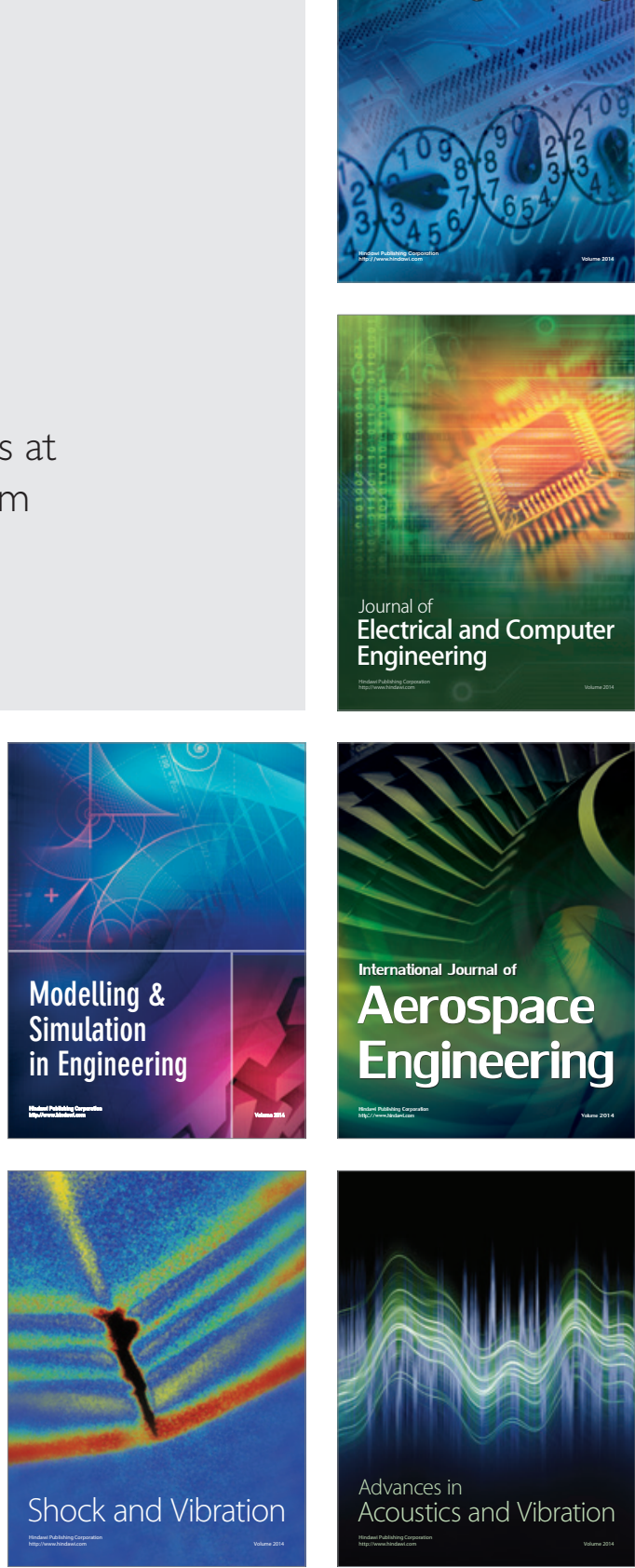